\title{
MODEL ESTIMATES FOR GENERATION AND DISTRIBUTION FROM NATIONAL TRAVELS OF TRANSPORT OF AIR CARGO BETWEEN MAJOR CITIES IN COLOMBIA
}

\author{
Hugo J. Mercado C. \\ Docente Universidad del Magdalena, Colombia. \\ Diego F. Suero P. \\ Docente Universidad Libre Barranquilla, Colombia.
}

\section{SUMMARY}

This paper presents models of generation, extraction and distribution of travel for air cargo between the main cities of Colombia. To develop the work we use information of cargo movement in Colombia during 2012, from then, we make the performance analysis and modeling to estimate future behavior considering possible scenarios. The generation model analyzed statistical variables such as population, distance between the main cities of Colombia, the gross domestic product of the cities, indicators of industrial density, the level of unemployment, among other characteristics to determine their influence on transport domestic air cargo.

For travel distribution model, including the gravitational, allowed to predict the behavior of air freight, under the hypothetical situation that the Colombian Caribbean coast will have a joint cargo airport that meets the needs of Barranquilla, Santa Marta and Cartagena. The results showed that despite the geographical situation of the cities, this is feasible, given that centralize the management of the three coastal cities in a specialized cargo airport could reduce generalized costs and encourage greater trade with the rest of the cities of Colombia, as demonstrated in the model.

\section{INTRODUCTION}

For modeling Colombian air cargo, we will consider the decision to travel (generation and attraction), and to a destination (distribution). For modeling of air cargo, the agents take decisions based on the maximization of their benefits, the product flow between consumers and producers, as well as in the air cargo paths for transporting goods, all under the platform based on trips and not in type of products.

The objective is to model the trips total generated (offer) and their demand, we used variables like the population size, number of jobs, income per capita, land use, etc. For trip generation 
model, we used lineal regression methods and methods of analysis by categories (Grange, Ibeas, \& González, 2009). The distribution models allow to estimate the number of trips made during a certain period of time, between different areas of the reporting system. In models of growth factor is part of a matrix "V" known. So we want to estimate the values of the matrix for a year, depending of the information you can use various methods (Ortuzar \& Willumsem, 2011).

Generally predict the number of trips made to certain destinations is important, because help to identify where the services need to be generated and allows the evaluation of the impact of changes in the patterns of demand for services (Blainey* \& Preston, 2010). The factor uniform method assumes that the entire matrix will grow evenly, according to a determinate growth factor; it is a little realistic situation unless it is a very short term. The methods of growth factor or doubly bounded, where there are two sets of growth factor each zone, origin and destination. For this we have develop a number of iterative methods, which use the Furness Method, introducing balancing factors.

The results show that aggregated data with different models differ slightly, but disaggregated data presents considerable differences. It was also shown that the level shift data aggregation significantly alter the values of the model parameters (Grange L. D., 2010). The distribution model best known is called transportation problem or Hitchcock (Hitchcock, 1941), in which the goods produced in the indicated origins to a number of destinations are provided at minimal cost. This model is formulated as a linear programming problem with constant costs.

The distribution model for gravity, as stated by Wilson (Wilson, 1970), it is the model where the entropy changes (the objective function) for a change of the trips generation or attraction, respectively are indicated. This type of entropy models has made great contributions to the study of the distribution of travel (Wang, Han Yao, \& Jing, 2006). The Lagrange multiplier, expresses the change in entropy for a variation of the unit in the total system cost, and can be interpreted as the trips cost. This relationship was generalized for large populations by Smith (Smith, 1990), and lately validated by Roy and Thill (Roy \& Thill, 2004). For calibration of gravity model, we use the iterative method of Hyman.

\section{INFORMATION ANALYSIS}

The source information for this study comes from the Civil Aeronautics of Colombia, air transportation office, sector work group, which presented statistics for 2012. In the domestic market $141.949 \mathrm{t}$ of cargo were transported, 3.26\% higher than 2011 but $10 \%$ lower than year 2010. The monthly performance over the year 2012 compared to the previous year, it presented much volatility, where the best performance was present in March (19.6\%) and its biggest drop in September (10.3\%). December ends with a fall of $5.2 \%$ compared to December 2011. 
The airline Avianca transported $36 \%$ of total domestic cargo, followed by Aerosucre with $16 \%$, Lan Colombia reached an $11 \%$ market share, thanks to $65 \%$ growth in cargo movement over the previous year. Stands out the Air Caribbean growth, where increase $100 \%$ the cargo carried in 2011. That information is about the main cities of Colombia, nineten in total: Bogotá, Medellín, Cali, Barranquilla, Bucaramanga, Cartagena, Pereira, Santa marta, Montería, Pasto, Valledupar, Neiva, Riohacha, Quibdó, Armenia, Manizales, Ibagué, Villavicencio y Cúcuta.

Similarly, all information about Colombian municipal population, unemployment, industrial density indicator, the gross domestic product of each of the regions under study, we take the National Administrative Department of statistics (DANE), who make planning, processing, collecting, analysis and dissemination of official statistics in Colombia.

Based on information existing air cargo movement in Colombia during year 2012, we perform analyzes and modeling to estimate future behavior towards considering possible scenarios and induce their general behavior. Statistical analysis of the model is extremely important to determinate how close the proposed simulation model of reality is.

\subsection{Application of linear regression model}

To prepare the cargo generation model, we search information projections of the Colombian population of the major cities under study, as well as socio-economic indicators of unemployment, gross domestic product and industrial density. We take the values of tons generated by each of cities during 2012 year, compared to the behavior of socio-economic variables considered produce that effect.

The table number 1, presents the air cargo values generated by the 19 major cities in Colombia, population, distances between theirs and the rest of the cities used in the study, unemployment rate (UR), industrial density (ID) per square kilometer and its gross domestic product (GDP).

Cities like Bogota, Medellin, Cali y Barranquilla, generate $87 \%$ of all domestic air cargo, they correspond to $67 \%$ of total population, they have the highest levels of industrial density and two of them (Bogota and Barranquilla), they have the unemployment levels below the national average ( $10.5 \%$ ). Significantly the cities like Bogota and Medellin have travel costs more economical due to its geographical location, below the average distance covered (14.000 $\mathrm{km}$ ), however Cali and Barranquilla are slightly above average. The central cities require less distance for the movement of cargo in the country, they are Manizales, Pereira, Armenia and Ibague. Villavicencio presents the highest gross domestic product per capita; however this is not reflected in the movement of air cargo. 


\begin{tabular}{|c|c|c|c|c|c|c|}
\hline Cities & $\begin{array}{c}\text { Air } \\
\text { Cargo }(\mathrm{t})\end{array}$ & Population & $\begin{array}{c}\text { Distances } \\
(\mathrm{Km})\end{array}$ & $\begin{array}{l}\text { UR } \\
(\%)\end{array}$ & $\begin{array}{c}\text { ID } \\
\text { (Business } \\
/ \mathrm{Km})\end{array}$ & $\begin{array}{l}\text { GDP } \\
\text { (Cop) }\end{array}$ \\
\hline Bogotá & 49.904 & 6.778 .691 & 11.958 & 9.5 & 1.560 & 20.337 .170 \\
\hline Medellin & 13.132 & 2.219 .861 & 11.251 & 12.2 & 1.673 & 13.206 .791 \\
\hline Barranquilla & 9.399 & 1.112 .889 & 15.738 & 8.2 & 1.400 & 9.632 .789 \\
\hline Cali & 10.588 & 2.075 .380 & 14.250 & 15.4 & 0,881 & 13.235 .336 \\
\hline Bucaramanga & 1.425 & 509.918 & 14.112 & 9.6 & 1.247 & 23.073 .299 \\
\hline Cartagena & 4.215 & 895.400 & 15.152 & 10.4 & 0,153 & 12.956 .603 \\
\hline Pereira & 1.096 & 428.397 & 11.049 & 16.8 & 0,146 & 9.365 .751 \\
\hline Santa Marta & 1.287 & 414.387 & 15.345 & 10.2 & 0,013 & 6.671 .840 \\
\hline Monteria & 868 & 381.284 & 14.447 & 13.3 & 0,004 & 6.571 .618 \\
\hline Pasto & 703 & 383.846 & 18.663 & 13.5 & 0,024 & 5.527 .604 \\
\hline Valledupar & 481 & 348.990 & 16.788 & 11.6 & 0,003 & 13.651 .954 \\
\hline Neiva & 257 & 315.332 & 13.996 & 11.8 & 0,021 & 10.797 .351 \\
\hline Rioacha & 278 & 169.311 & 18.023 & 10.9 & 0,001 & 9.614 .465 \\
\hline Quibdo & 310 & 109.121 & 16.387 & 18.6 & 0,000 & 6.815 .440 \\
\hline Armenia & 201 & 272.574 & 11.230 & 17.3 & 0,260 & 8.435 .926 \\
\hline Manizales & 159 & 368.433 & 10.828 & 13.3 & 0,210 & 9.153 .629 \\
\hline Ibague & 109 & 495.246 & 11.446 & 17.1 & 0,047 & 9.851 .452 \\
\hline Villavicencio & 47 & 384.131 & 14.203 & 11.6 & 0,019 & 38.662 .154 \\
\hline Cucuta & 12 & 585.543 & 17.208 & 15.4 & 0,071 & 7.705 .850 \\
\hline Total & 94.473 & 18.248 .734 & 272.074 & 13.0 & 7,733 & 235.267 .022 \\
\hline
\end{tabular}

Table 1-DANE, civil aviation

Using Statraphics tool, we obtain the data presented in table 2, results in the Multiple Linear Regression modeling. The output shows the results of fitting a multiple regression model to describe the relationship between kilograms (thousands) total air cargo and five independent variables. Because of " $\mathrm{P}$ " value less than 0.05 , there is a statistically significant relationship between the variables with a confidence level of $95 \%$. The R-squared statistic adjusted model explains $98.47 \%$ of the total variability of air cargo. However, the model is capable of being improved, because the IDI variable has $\mathrm{P}$ value above 0.5 , therefore that term is not statistically significant and can subtract model. Likewise the GDP, has a negative sign as input 
to the model of air cargo, unrealistic and logical situation, it is expected that the higher level of per capita incomes rise the load generated by the city.

\begin{tabular}{|l|l|l|l|l|}
\hline & & Error & Statistical & \\
\hline Parameters & Estimate & Standar & $\boldsymbol{T}$ & $\boldsymbol{P}$ Valor \\
\hline Constant & 447,928 & 4038,52 & 0,110914 & 0,9134 \\
\hline Population & 0,00750504 & 0,000307698 & 24,3909 & 0,0000 \\
\hline Distances & 0,0346918 & 0,163766 & 0,211838 & 0,8355 \\
\hline UR & $-199,133$ & 144,941 & $-1,37389$ & 0,1927 \\
\hline GDP & $-0,0000488865$ & 0,0000482741 & $-1,01269$ & 0,3297 \\
\hline ID & 24,7883 & 853,09 & 0,0290571 & 0,9773 \\
\hline
\end{tabular}

Table 2-Results Multiple Linear Regression

\subsection{Application of the gravity model}

For the preparation of gravitational distribution model, we start from the origin destination matrix of Colombian air cargo. All sending and receiving tons by each 19 main cities of Colombia, under study. Considering the distance existing between each of the cities in kilometers and assuming that the transportation costs between cities are in direct relation to their distances, we set the origin-destination cost between cities.

Starting costs matrix, we established $\mathrm{C}^{*}$, corresponding to the average cost matrix and in turn determine the parameter $\beta 0$, corresponding to the inverse of the average cost. We clarify that the cost function we assume for the development of the model is the exponential $\left(\exp \left(-\beta \mathrm{C}_{\mathrm{ij}}\right)\right)$. From this function we determinate the corresponding matrix, to determinate the correction factor calculated by the ratio of total cargo and function.

By affectation factor correction matrix function, we established the first origin-destination matrix, which by successive iterations values closer to the actual value of the cargo. This procedure is performed also to very close to the average cost values, using calibration method of Hyman.

In table number 3, we determine the values simulated of the air cargo of the main cities of Colombia. Addition, we determinate the parameter value $\beta$, which minimizes the function of costs, the value founded is 0.0007 . To verify the proposed matches with the actual data model, we performed a statistical hypothesis test (Wilcoxon test) which yielded the following results:

The null hypothesis for alpha $=0.05$ is not rejected. 


\begin{tabular}{|l|r|r|}
\hline \multicolumn{1}{|c|}{ Oi/Dj } & Real Air cargo $(\mathrm{t})$ & Simulated \\
\hline Bogotá & 33.562 & 38.223 \\
\hline Medellin & 14.116 & 12.614 \\
\hline Barranquilla & 10.287 & 9.399 \\
\hline Cali & 11.394 & 10.136 \\
\hline Bucaramanga & 1.586 & 1.425 \\
\hline Cartagena & 4.280 & 3.980 \\
\hline Pereira & 1.214 & 1.094 \\
\hline Santa Marta & 1.383 & 1.287 \\
\hline Monteria & 938 & 867 \\
\hline Pasto & 776 & 703 \\
\hline Valledupar & 531 & 481 \\
\hline Neiva & 288 & 257 \\
\hline Rioacha & 300 & 278 \\
\hline Quibdo & 339 & 310 \\
\hline Armenia & 224 & 201 \\
\hline Manizales & 177 & 159 \\
\hline Ibague & 121 & 109 \\
\hline Villavicencio & 53 & 47 \\
\hline Cucuta & 1.583 & 2012 \\
\hline Total & & 1253 \\
\hline
\end{tabular}

Table 3- Results gravitational modeling and air cargo 2012

\section{Geographic location of a new cargo airport of the north Colombian coast}

To effect of simulate the behavior of air cargo between the main cities of the north Colombian coast, Barranquilla, Cartagena and Santa Marta, In the likely event that through of government policies we will use only an airport of air cargo to the three cities, in addition, their move will be increase in a $20 \%$ in front of the rest of the cities of Colombia. The modeling results are presented on the table number 4 .

According to this modeling of the scenario, the distribution of air cargo from Barranquilla to the rest of the cities of Colombia, would go from 9.398 t to $11.035 \mathrm{t}$. Cartagena in turn would go from 3.980 t to $4.722 \mathrm{t}$, and Santa Marta from 1.287 t to $1.544 \mathrm{t}$. Equally, the model illustrates the behavior of the air cargos for each of the cities around the country with the main cities of the north coast. 


\begin{tabular}{|c|c|c|c|c|}
\hline $\mathrm{Oi} / \mathrm{Dj}$ & Barranquilla & Cartagena & Santa Marta & Total \\
\hline Bogotá & 8.792 & 3.771 & 1.265 & 13.827 \\
\hline Medellin & 1.109 & 406 & 133 & 1.718 \\
\hline Barranquilla & 0 & 0 & 0 & 0 \\
\hline Cali & 651 & 279 & 78 & 1.008 \\
\hline Bucaramanga & 115 & 40 & 15 & 170 \\
\hline Cartagena & 0 & 0 & 0 & 0 \\
\hline Pereira & 65 & 28 & 8 & 101 \\
\hline Santa Marta & 0 & 0 & 0 & 0 \\
\hline Monteria & 105 & 45 & 13 & 163 \\
\hline Pasto & 41 & 17 & 10 & 68 \\
\hline Valledupar & 48 & 23 & 9 & 80 \\
\hline Neiva & 12 & 5 & 1 & 18 \\
\hline Rioacha & 42 & 15 & 6 & 63 \\
\hline Quibdo & 25 & 11 & 3 & 38 \\
\hline Armenia & 11 & 5 & 1 & 17 \\
\hline Manizales & 10 & 4 & 1 & 15 \\
\hline Ibague & 6 & 2 & 1 & 9 \\
\hline Villavicencio & 3 & 1 & 0 & 4 \\
\hline Cucuta & 1 & 0 & 0 & 1 \\
\hline Total & 11.035 & 4.722 & 1.544 & \\
\hline
\end{tabular}

Table 8-gravity model air cargo hypothetical scenario

In order to estimate the approximate location of a possible airport between the cities of Barranquilla, Cartagena and Santa Marta, we use the expression of center mass to locate the location coordinates. We perform estimates using the number of trips, people and cargo handled between the three cities, and the distances are dimensionless according to the scale of a commercial world atlas. Formula for calculating the center of mass (Caicedo, 2014):

$$
\mathrm{x}_{\mathrm{C}}=\frac{\mathrm{m}_{\mathrm{c}\left(\mathrm{x}_{\mathrm{i}}, \mathrm{y}_{\mathrm{i}}\right)}+\mathrm{m}_{\mathrm{b}\left(\mathrm{x}_{\mathrm{i}}, \mathrm{y}_{\mathrm{i}}\right)}+\mathrm{m}_{\mathrm{sm}\left(\mathrm{x}_{\mathrm{i}}, \mathrm{y}_{\mathrm{i}}\right)}}{\mathrm{M}}
$$

The results showed different location but close together. The population is locating between Cartagena and Barranquilla, aspect that was predicted due to higher travel, freight and population than Santa Marta.

In Figures 1 present geographic locations using Google Maps web application. 


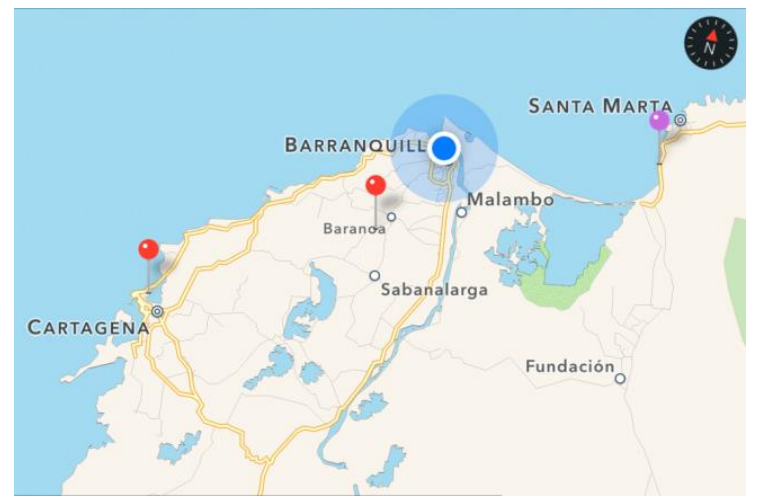

\section{Figure 1- Geographic location specialized cargo airport of the north Colombian coast}

Although even though the geographical location of cities located between 900 and $1.000 \mathrm{~km}$ is not the best, because of its higher costs, Barranquilla stands out as having one of the busiest air cargos. For this reason, the hypothetical situation presented in the modeling, is attractive, since centralized management burden of the three coastal cities in a specialized cargo airport could reduce generalized costs and encourage more trade with the rest of the cities of Colombia, as we demonstrated in the modeling. One of the interesting findings is the identification of a need in the future of an air cargo terminal equidistant between the cities Barranquilla and Cartagena, also it could be located in towns like Santa Catalina Bolivar, Colombia, consisting of proper access roads and land suitable for construction.

\section{BIBLIOGRAFÍA}

Blainey*, S. P., \& Preston, J. (2010). Modelling local rail demand in South Wales. Transportation Planning and Technology, vol. 33 No 1.

Caicedo, M. I. (2014, Enero 20). Sistemas de Partículas I, centros de masa y teoría del momentum.Retrieved from Universidad Simón Bolivar: http://www.fis.usb.ve/

Cohon, J. (1978). Multiobjective Programming and Planning. Academic Press.

Grange, L. D. (2010). A consolidated model of trip distribution. Transportation research, 61-75.

Grange, L. d., Ibeas, A., \& González, F. (2009). A Hierarchical Gravity Model with Spatial Correlation Mathematical Formulation and Parameter Estimation. Springer Science + Business Media, s11067-008-9097-0.

Hitchcock, F. (1941). The distribution of a product from several sources to numerous localities. Journal of Mathematics and Physics, 224-230.

Ortuzar, J., \& Willumsem, L. (2011). Modelling Transport. Santiago. 
Roy, J., \& Thill, J. (2004). Spatial interaction modelling. Papers in Regional Science 83, 339-361.

Smith, T. (1990). Most-probable-state-analysis: a method for testing probabilistic theories of population behaviour. New Frontiers in Regional Science.

Wang, D.-H., Han Yao, R., \& Jing, C. (2006). Entropy Models of Trip Distribution. JOURNAL OF URBAN PLANNING AND DEVELOPMENT.

Wilson, A. (1970). Entropy in Urban and Regional Modeling. London: Pion. 